\title{
Generation of mathematical models for estimating losses generated in an IPTV transmission system using the RTSP protocol
}

\author{
Jordi R. Rodríguez ${ }^{\# 1}$, Danilo A. López $\mathrm{S}^{\# 2}$, Jaime V. Avellaneda ${ }^{\# 3}$ \\ ${ }^{\# 1}$ Electronic Engineering, Universidad Distrital Francisco José de Caldas, \\ Faculty of Engineering, Bogotá (Colombia-South America) \\ jordirico89@correo.udistrital.edu.co \\ ${ }^{\# 21}$ FullTime Professor at Universidad Distrital Francisco José de Caldas, \\ Faculty of Engineering, Bogotá (Colombia-South America) \\ dalopezs@udistrital.edu.co \\ \#3 Electronic Engineering, Universidad Distrital Francisco José de Caldas, \\ Faculty of Engineering, Bogotá (Colombia-South America) \\ javallejo@correo.udistrital.edu.co
}

Abstract - In this article different mathematical models are implemented (using linear regression) in order to estimate or predict the losses that can be produced when delivering television and video content on demand on an IPTV-IMS platform using the RTSP protocols. Several scenarios are evaluated for this. Initially, television is broadcast using the RTSP protocol, switching between wireless and wired networks, and varying the network load. Later this process is repeated when video is transmitted on demand repeating the load conditions and type of network. Each of the proposed scenarios starts with a user receiving the transmission and ends when 10 users are connected. The results of these tests are tabulated, plotted and compared in order to determine how successful the estimation models developed are.

Keyword-Losses on an IPTV system, Mathematical model, IPTV, RTSP,

\section{INTRODUCTION}

The network structures developed included the implementation of an IPTV system over a wired network structure (see Fig. 1) and over a wireless network topology (Fig. 2).

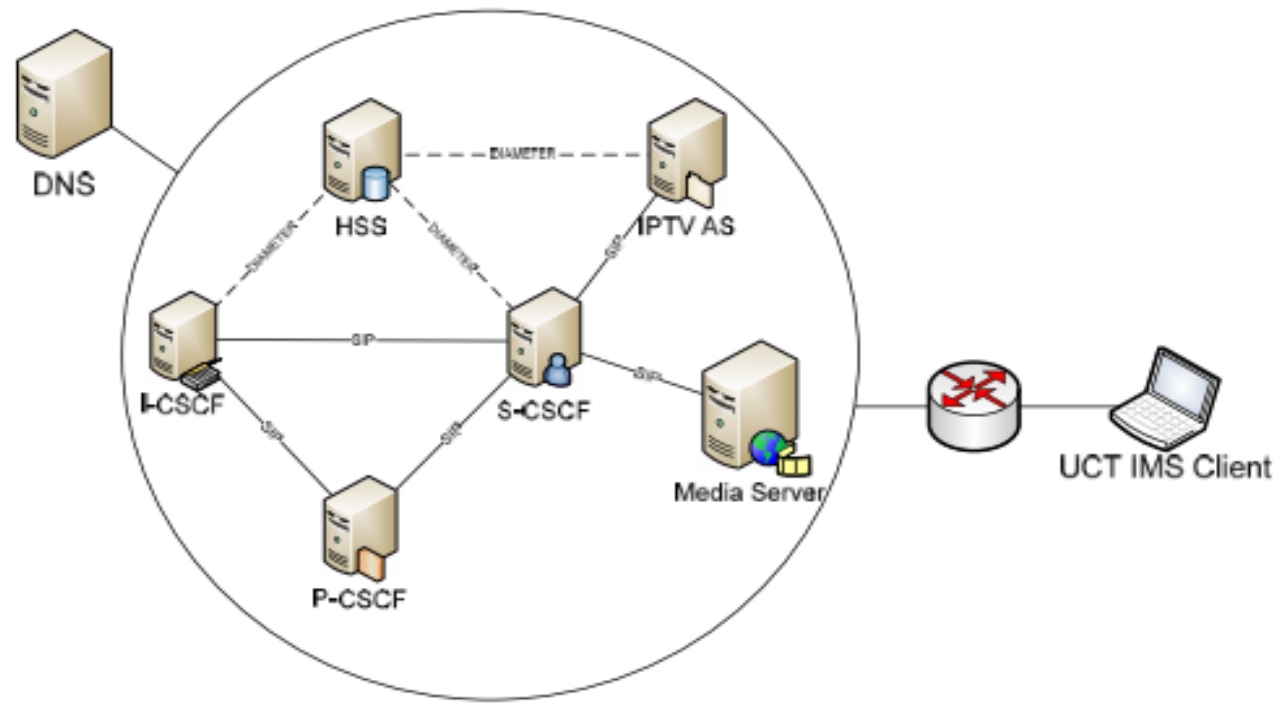

Fig. 1. Scenario used for the implementation of the IPTV system in a wired network [1]. 


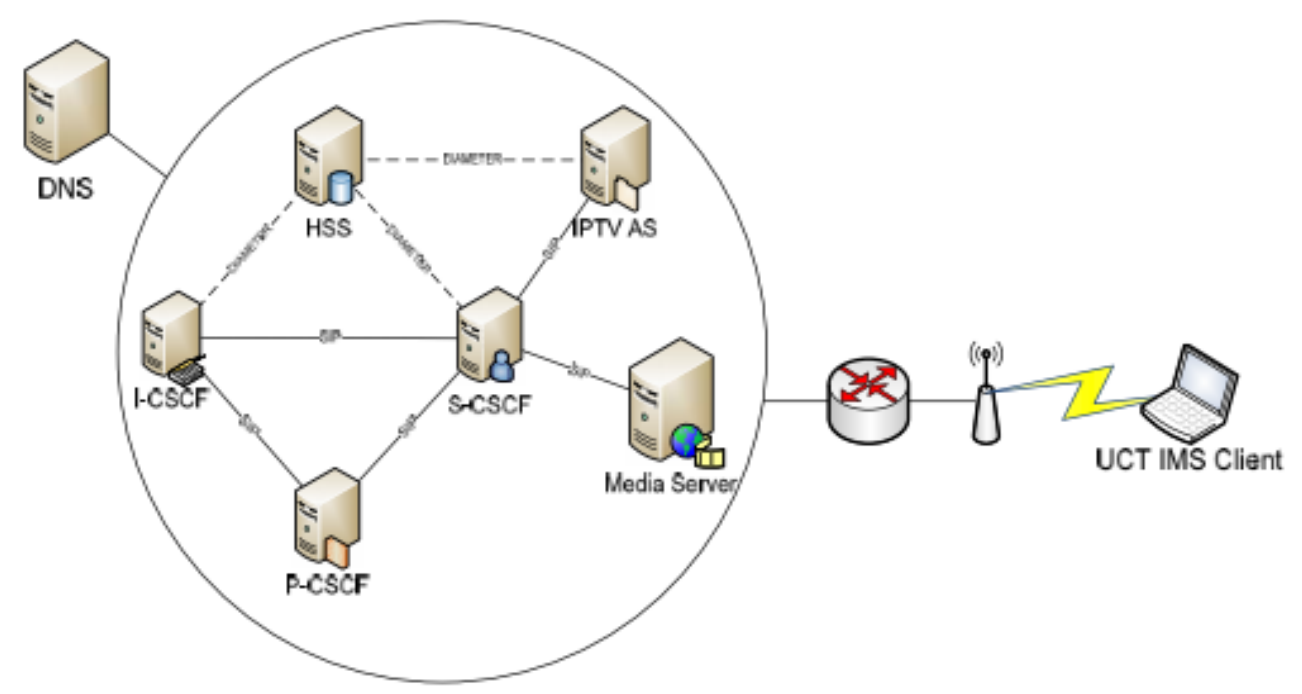

Fig. 2. Scenario used for the implementation of the IPTV system in wireless network [1].

With the network infrastructure already established, the next step is to determine the scenarios to perform the measurement and generation of the behavior of the variable that we want to estimate. Since we intend to estimate or predict the behavior of the variable losses in reception, the RTSP (Real Time Streaming Protocol) protocol [2] was used, which generally works on the UDP standard (User Datagram Protocol) of the transport layer. The measurements made were applied independently for the television and video on demand (VoD) services given that the bandwidth consumption may be different. The traffic sent for the tests corresponds to a single video in mp4 format, with a duration of 45 minutes, without high definition and will be used both for television and VoD so that the behavior of the variables is not affected by it. There will also be traffic corresponding to instant messaging although this does not represent a significant load to affect the measured variables.

Initially, each of the users will correspond to a computer with the IMS client [3] installed connected to the wired network. Subsequently, the scenarios will be repeated with the clients connected to the wireless network, which aims to see the effect with respect to the previous case.

Initially, each of the users will correspond to a computer with the IMS client [4] installed and connected to the wired network. Subsequently, the scenarios will be repeated with the clients connected to the wireless network, which aims to see the effect with respect to the previous case.

It is important to note that the implementation of the IPTV platform on Fig. 1 and 2 corresponds to the installation of the selected project (Open IMS Core) [4] with its additional entities, the configuration of each one so that they work on different machines with the domain of the District University and the start-up of each of the proposed scenarios with the respective loss measurements. For this installation, we worked on a data blade of the High Performance Computing Center of the university, for which each of the necessary machines was virtualized using the open source software VirtualBox [5]. In each one Ubuntu 8.04 was installed since the chosen project was designed to work originally under this distribution.

\section{Materials AND Method}

In order to implement the loss model, it became necessary to transmit both television and video-on-demand signals over the network structures of Fig. 1 and 2; the results are shown in Fig 3 to 6. 


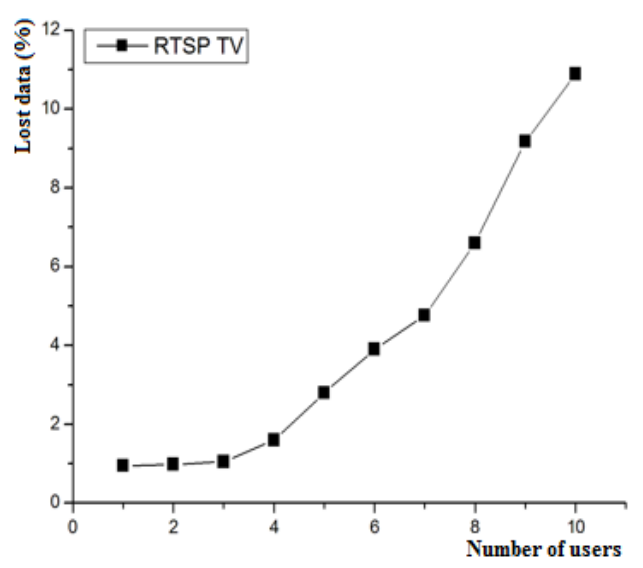

Figure 3. Behavior of the losses variable for television signals sent through the RTSP protocol through wireless network.

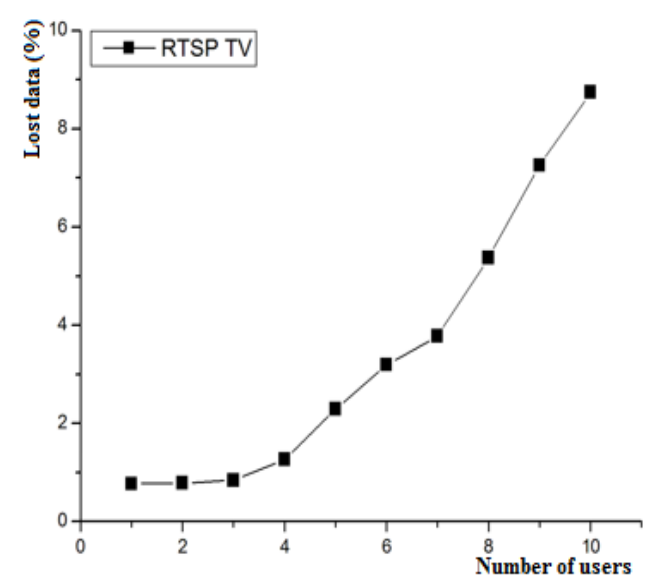

Figure 5. Behavior of the loss variable for television signals sent through the RTSP protocol through a wired network.

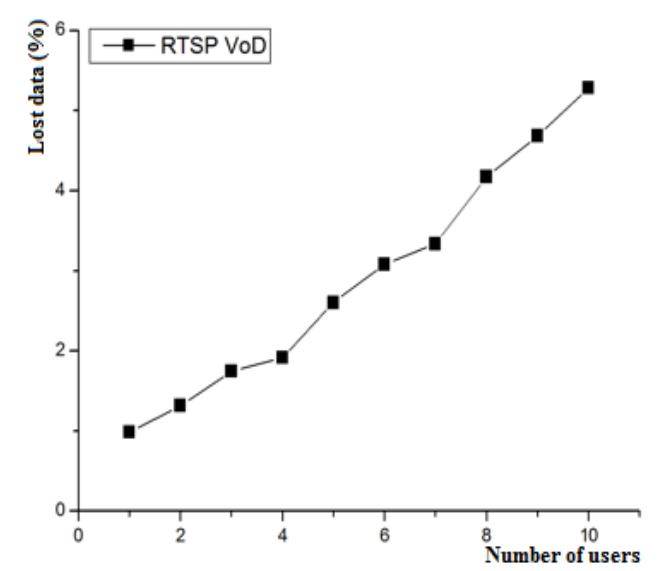

Figure 4. Behavior of the lossesvariable for VoD signals sent through the RTSP protocol through wireless network

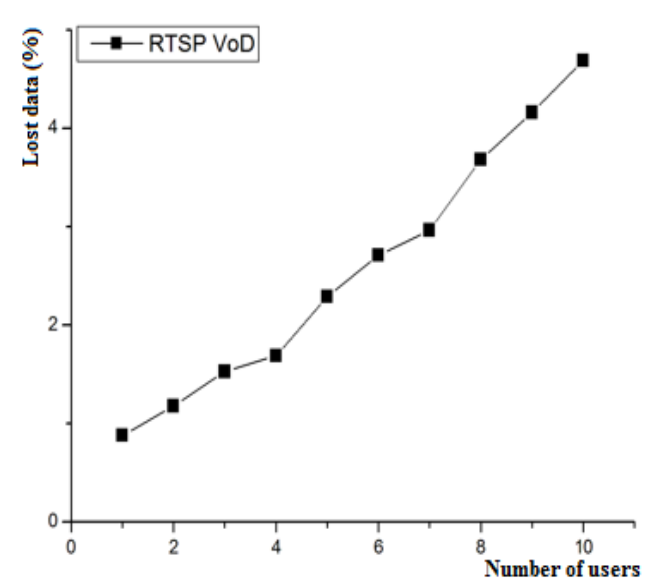

Figure 6. Behavior of the variable losses for VoD signals sent through the RTSP protocol through a wired network.

With the loss data already tabulated, we proceeded to obtain a mathematical model that allows us to estimate its behavior having as input parameters the number of users of different types, that is, the number of users connected to the platform through a wireless network, those connected by a wired network and the amount of Set Top Boxes associated with televisions.

It should be noted that the loss models are implemented for each of the services provided (VoD and television) when the data is sent on the RTSP standard, so that in the end there will be 4 different final equations.

Since the data were obtained experimentally, it was decided to use the concept of linear regression to obtain the most accurate approximation possible for each of Fig. 3 thru 6. However, since these do not represent linear functions per se, it is necessary to perform transformations of variables in order to approximate them to linear functions.

There are several methodologies available that can be adjusted to different types of graphics. In order to select the most suitable one, different transformations were made on the data and those that generated a figure close to a straight line were chosen. Later the equation of each case was found and the data of slope (P) and cut point (C) that were used within each model were extracted. The models used for the results obtained are presented in Table I. 
TABLE I. Models of Transformation of Variables.

\begin{tabular}{|c|c|c|}
\hline Model & $\begin{array}{l}\text { New axes to achieve the straight line } \\
\text { with the original dispersion function }\end{array}$ & $\begin{array}{l}\text { Model parameters, taken from the } \\
\text { linearized function }\end{array}$ \\
\hline$y=a x^{b}$ & $\begin{aligned} Y & =\log _{B}(y) \\
X & =\log _{B}(x)\end{aligned}$ & $\begin{array}{c}a=\log _{B}^{-1}(C) \\
b=P\end{array}$ \\
\hline$y=a x^{b}+\delta$ & $\begin{array}{c}Y=\log _{B}(y-\delta) \\
X=\log _{B}(x)\end{array}$ & $\begin{array}{c}a=\log _{B}^{-1}(C) \\
b=P\end{array}$ \\
\hline$y=B^{a x+d}$ & $\begin{array}{c}Y=\log _{B}(y) \\
X=x\end{array}$ & $\begin{aligned} a & =P \\
d & =C\end{aligned}$ \\
\hline$y=B^{a x+d}+\delta$ & $\begin{array}{c}Y=\log _{B}(y-\delta) \\
X=x\end{array}$ & $\begin{array}{l}a=P \\
d=C\end{array}$ \\
\hline$y=a_{0}+a_{1} x+a_{2} x^{2}$ & $\begin{array}{c}Y=\frac{\left(y-y_{1}\right)}{\left(x-x_{1}\right)} \\
X=x\end{array}$ & $\begin{array}{c}a_{2}=P \\
a_{1}=C-P x_{1} \\
a_{0}=y_{1}-C x_{1}\end{array}$ \\
\hline$y=\frac{x}{a x+b}$ & $\begin{aligned} Y & =\frac{1}{y} \\
X & =\frac{1}{x}\end{aligned}$ & $\begin{array}{l}a=C \\
b=P\end{array}$ \\
\hline
\end{tabular}

\section{RESULTS}

A. Losses model for television signals sent through the RTSP protocol through a wireless network.

For this case, the following transformation of variables is performed:

$$
X=x Y=\frac{y-y_{1}}{x-x_{1}}
$$

Where $a_{0}=y_{1}-C x_{1}, a_{1}=C-P x_{1}$ y $a_{2}=P$

The obtained straight line equation is therefore:

$$
y=0,1428 x-0,3087
$$

Now we can proceed to determine the constants.

$$
a_{0}=1,254 \quad a_{1}=-0,451 \quad a_{2}=0,1428
$$

Therefore the final model is given by the equation:

$$
\% \text { lossess }=1,254-0,451 *(\# \text { wireless users })+0,142(\text { \#wireless users })^{2}
$$

The data obtained with this model are presented in Table II and its representation in Fig. 7.

TABLE II. Results of the model generated for Television over RTSP through wireless network.

\begin{tabular}{|c|c|c|c|c|}
\hline User & Losses (\%) & Approximation & Absolute Error & Relative Error \\
\hline 1 & 0,94560453 & 0,9456 & 0 & 0 \\
\hline 2 & 0,982126573 & 0,9225 & $-0,059622$ & 6,07071 \\
\hline 3 & 1,042910924 & 1,185 & 0,14209361 & 13,6247 \\
\hline 4 & 1,5975424 & 1,7331 & 0,13556213 & 8,48567 \\
\hline 5 & 2,7989313 & 2,5668 & $-0,2321268$ & 8,29341 \\
\hline 6 & 3,8991423 & 3,6861 & $-0,2130378$ & 5,46371 \\
\hline 7 & 4,75813123 & 5,091 & 0,3328733 & 6,99588 \\
\hline 8 & 6,5959313 & 6,7815 & 0,18557323 & 2,81345 \\
\hline 9 & 9,18253134 & 8,7576 & $-0,4249268$ & 4,62756 \\
\hline 10 & 10,89060635 & 11,0193 & 0,12869818 & 1,18174 \\
\hline \multicolumn{5}{r}{} \\
\cline { 3 - 4 }
\end{tabular}


B.Losses model for video signals on demand sent by the RTSP protocol and through wireless network.

For this case, the following transformation of variables is performed:

$$
X=x Y=\log _{B} y
$$

The obtained straightline equation is therefore:

$$
Y=a X+b \quad \rightarrow \quad \log _{B} y=a x+b
$$

And the new y value is determined:

$$
B^{\log _{B} y}=B^{a x+b} \quad \rightarrow \quad y=B^{a x+b}
$$

Where $a=P$ y $b=C$

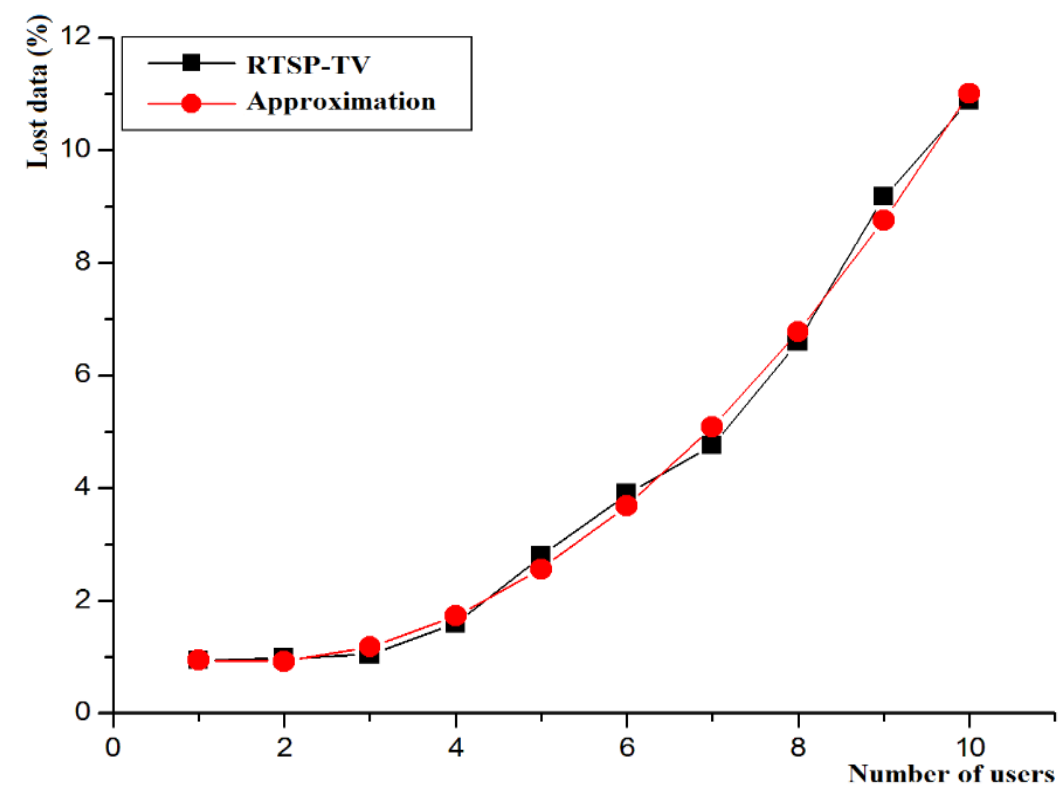

Figure. 7. Approximation for television sent through RTSP protocol through wireless network. - Average relative error 5,75\%.

The obtained straightline equation is:

$$
y=0,5197 x-0,0348
$$

Now we can proceed to determine the constants.

$$
a=0,5197 \quad b=-0,0348
$$

Therefore the final model is given by the equation:

$$
\% \text { losses }=10^{0,5197(\# \text { wireless users })-0,0348}
$$

The data obtained with this model are presented in Table III and its representation in Fig. 8.

TABLE III. Results of the model generated for VoD over RTSP through wireless network.

\begin{tabular}{|c|c|c|c|c|}
\hline User & Losses (\%) & Approximation & $\begin{array}{c}\text { Absolute } \\
\text { Error }\end{array}$ & $\begin{array}{c}\text { Relative } \\
\text { Error }\end{array}$ \\
\hline 1 & 0,9851454 & 1,1215018 & 0,13635645 & 13,84125106 \\
\hline 2 & 1,3131189 & 1,3467906 & 0,03367141 & 2,564231919 \\
\hline 3 & 1,7453451 & 1,617335 & $-0,12801009$ & 7,334371139 \\
\hline 4 & 1,9143244 & 1,942227 & 0,02790260 & 1,457569126 \\
\hline 5 & 2,6015533 & 2,332383 & $-0,26916958$ & 10,34649521 \\
\hline 6 & 3,0799135 & 2,800915 & $-0,27899804$ & 9,058632478 \\
\hline 7 & 3,3369155 & 3,363566 & 0,02665085 & 0,798667437 \\
\hline 8 & 4,1722551 & 4,039243 & $-0,13301195$ & 3,188011023 \\
\hline 9 & 4,686746 & 4,8506506 & 0,16390468 & 3,497195709 \\
\hline 10 & 5,284053 & 5,8250545 & 0,54100156 & 10,23838268 \\
\hline
\end{tabular}




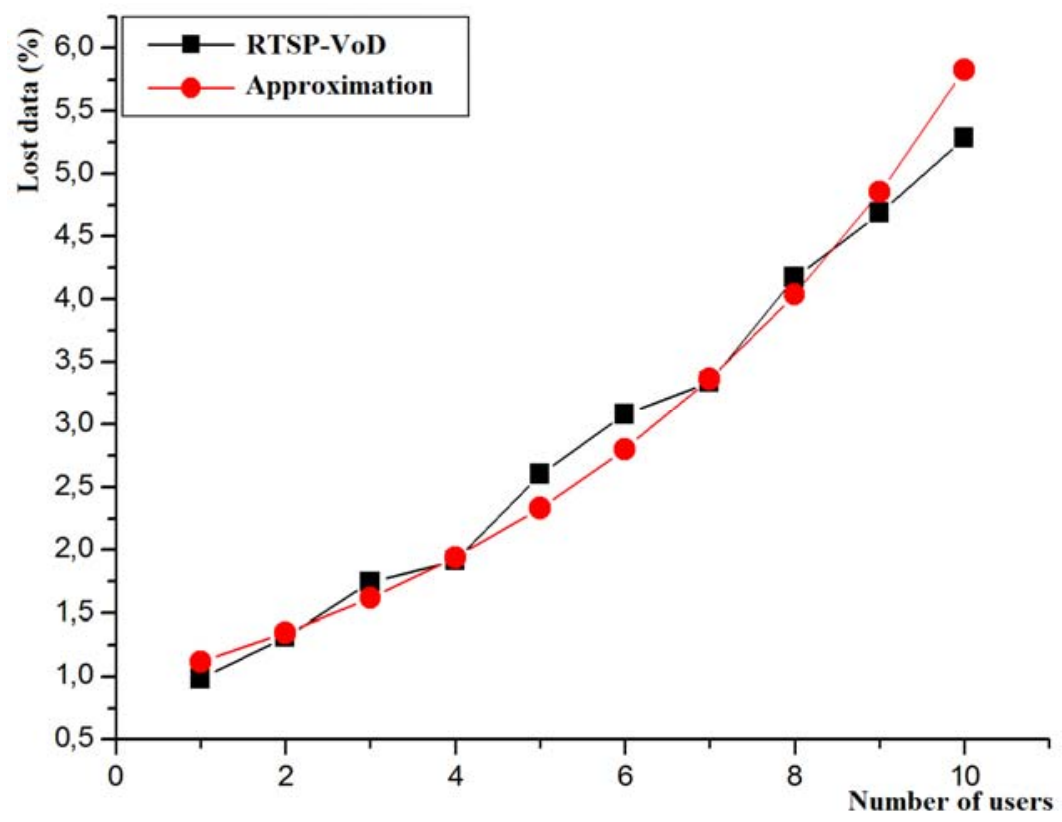

Figure. 81. Approximation for VoD sent via RTSP protocol through wireless network. - Average relative error 6,23\%

C. Losses model for television traffic sent through the RTSP protocol and through a wired network.

In this case, the results are lower than those obtained by wireless transmission and according to their graphs, it can be seen that they have very similar behavior. This is consistent since only the transmission medium is being changed to a more reliable one. Given this, since the losses are smaller but have similar behaviors, we verified if these vary in some percentage when using cable as a means of transmission. The results are shown in Table IV below.

TABLE IV. Ratio between losses for television by RTSP via wireless and wired network.

\begin{tabular}{|c|c|c|c|}
\hline Users & $\begin{array}{c}\text { Wireless Network } \\
\text { Losses (\%) }\end{array}$ & $\begin{array}{c}\text { Wired Network } \\
\text { Losses (\%) }\end{array}$ & Ratio (\%) \\
\hline 1 & 0,94560453 & 0,77201295 & 81,6423 \\
\hline 2 & 0,982126573 & 0,783056148 & 79,7307 \\
\hline 3 & 1,042910924 & 0,842462075 & 80,7799 \\
\hline 4 & 1,5975424 & 1,26401851 & 79,1227 \\
\hline 5 & 2,7989313 & 2,291823204 & 81,8821 \\
\hline 6 & 3,8991423 & 3,191329872 & 81,847 \\
\hline 7 & 4,75813123 & 3,777712212 & 79,3949 \\
\hline 8 & 6,5959313 & 5,374938794 & 81,4887 \\
\hline 9 & 9,18253134 & 7,257867839 & 79,0399 \\
\hline 10 & 10,89060635 & 8,743512012 & 80,2849 \\
\hline
\end{tabular}

It is easy to appreciate that losses when using cable as a means of transmission correspond approximately to $80 \%$ of those obtained when receiving wirelessly, or what is the same, the losses are reduced by $20 \%$. For this reason, the same model generated for wireless transmission will be used multiplying it by 0.8 (see equation 3 ).

The model in this case will be:

$$
\% \text { losses }=0,8 *\left(1,254-0,451 *(\# \text { copper users })+0,142(\# \text { copper users })^{2}\right)
$$

The data obtained with this model are presented in Table $\mathrm{V}$ and its representation in Fig. 9. 
TABLE V. Results of the model generated for television by RTSP through wired network.

\begin{tabular}{|c|c|c|c|c|}
\hline User & Losses (\%) & Approximation & Absolute Error & Relative Error \\
\hline 1 & 0,772012 & 0,75648 & 0,01553 & 2,01154 \\
\hline 2 & 0,783056 & 0,73800 & 0,04505 & 5,75342 \\
\hline 3 & 0,842462 & 0,94800 & $-0,10554$ & 12,5278 \\
\hline 4 & 1,2640185 & 1,38648 & $-0,12247$ & 9,68855 \\
\hline 5 & 2,291823 & 2,05344 & 0,23838 & 10,4013 \\
\hline 6 & 3,191329 & 2,94888 & 0,24245 & 7,59703 \\
\hline 7 & 3,777712 & 4,07280 & $-0,29509$ & 7,81138 \\
\hline 8 & 5,374938 & 5,42520 & $-0,05026$ & 0,93517 \\
\hline 9 & 7,257867 & 7,00608 & 0,25178 & 3,46912 \\
\hline 10 & 8,743512 & 8,81544 & $-0,07193$ & 0,82269 \\
\hline & & & Average & 6,108 \\
\hline
\end{tabular}

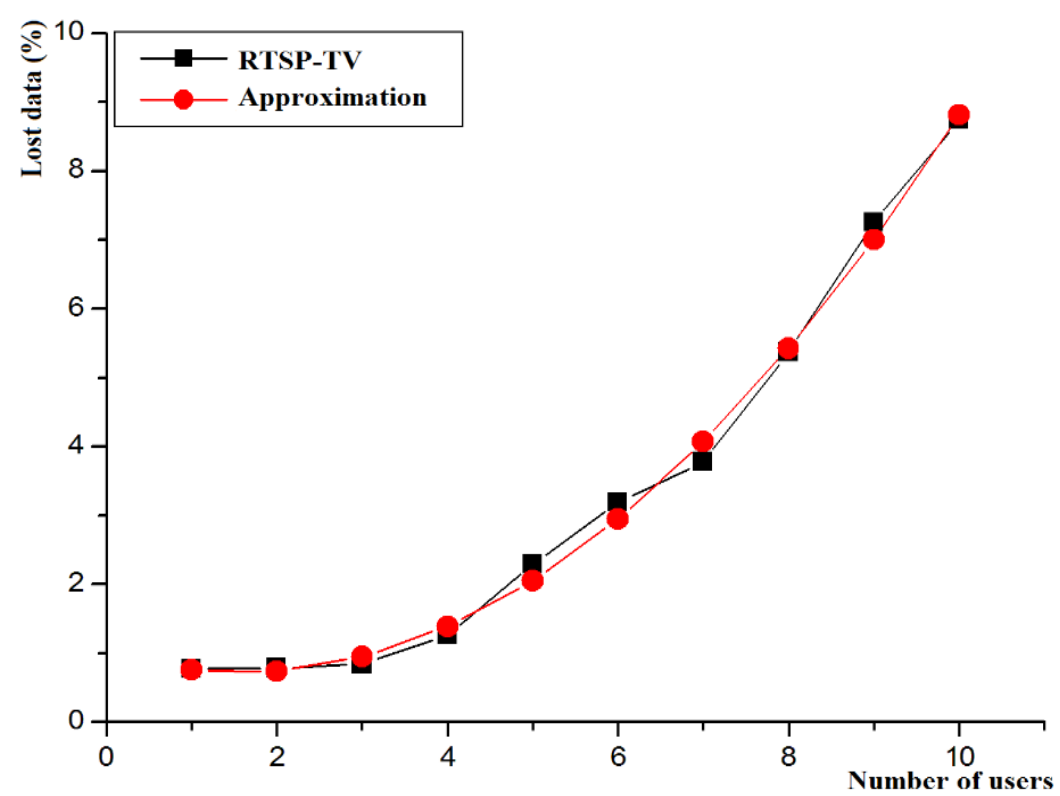

Figure 9. Approximation for television sent through RTSP protocol through wired network. - Average relative error 6,1\%. D. Losses model for video on demand sent through the RTSP protocol and through a wired network. Carrying out an analysis as in the previous case, we obtain the results shown in Table VI.

TABLE VI. Ratio between losses for VoD by RTSP via wireless and wired network.

\begin{tabular}{|c|l|l|l|}
\hline Users & \multicolumn{1}{|c|}{$\begin{array}{c}\text { Wireless Network } \\
\text { Losses (\%) }\end{array}$} & $\begin{array}{c}\text { Wired Network } \\
\text { Losses (\%) }\end{array}$ & Ratio (\%) \\
\hline 1 & 0,985145414 & 0,879980167 & 89,3249 \\
\hline 2 & 1,313118947 & 1,180691956 & 89,9151 \\
\hline 3 & 1,745345147 & 1,52911417 & 87,611 \\
\hline 4 & 1,914324455 & 1,689050397 & 88,2322 \\
\hline 5 & 2,6015533 & 2,288451119 & 87,9648 \\
\hline 6 & 3,0799135 & 2,711741692 & 88,046 \\
\hline 7 & 3,3369155 & 2,962890612 & 88,7913 \\
\hline 8 & 4,17225513 & 3,682117724 & 88,2525 \\
\hline 9 & 4,686746 & 4,160169547 & 88,7646 \\
\hline 10 & 5,284053024 & 4,68617418 & 88,6852 \\
\hline
\end{tabular}


Taking Table VI as a reference, it is concluded that when using cable as a transmission medium the losses are reduced by $12 \%$ with respect to the wireless medium, which implies that the model of equation 8 must be multiplied by 0.88 to adjust to the VoD flow

The model in this case would be:

$$
\% \text { losses }=0,88 *\left(10^{0,5197(\text { \#copper users })-0,0348}\right)
$$

The data obtained with this model are presented in Table VII and its representation in Fig. 10.

TABLE VII. Results of the model generated for VoD by RTSP through wired network.

\begin{tabular}{|c|c|c|c|c|}
\hline User & Losses (\%) & Approximation & Absolute Error & Relative Error \\
\hline 1 & 0,8799801 & 0,986921641 & 0,10694 & 12,1527 \\
\hline 2 & 1,1806919 & 1,185175519 & 0,00448 & 0,37974 \\
\hline 3 & 1,5291141 & 1,423254849 & $-0,1059$ & 6,92292 \\
\hline 4 & 1,6890503 & 1,70915981 & 0,02011 & 1,19058 \\
\hline 5 & 2,2884511 & 2,052497667 & $-0,236$ & 10,3106 \\
\hline 6 & 2,7117416 & 2,464805601 & $-0,2469$ & 9,10618 \\
\hline 7 & 2,9628906 & 2,959938395 & $-0,003$ & 0,09964 \\
\hline 8 & 3,6821177 & 3,554533995 & $-0,1276$ & 3,46496 \\
\hline 9 & 4,1601695 & 4,268572598 & 0,1084 & 2,60574 \\
\hline 10 & 4,6861748 & 5,126048042 & 0,43987 & 9,38663 \\
\hline & & & Average & 5,562 \\
\hline
\end{tabular}

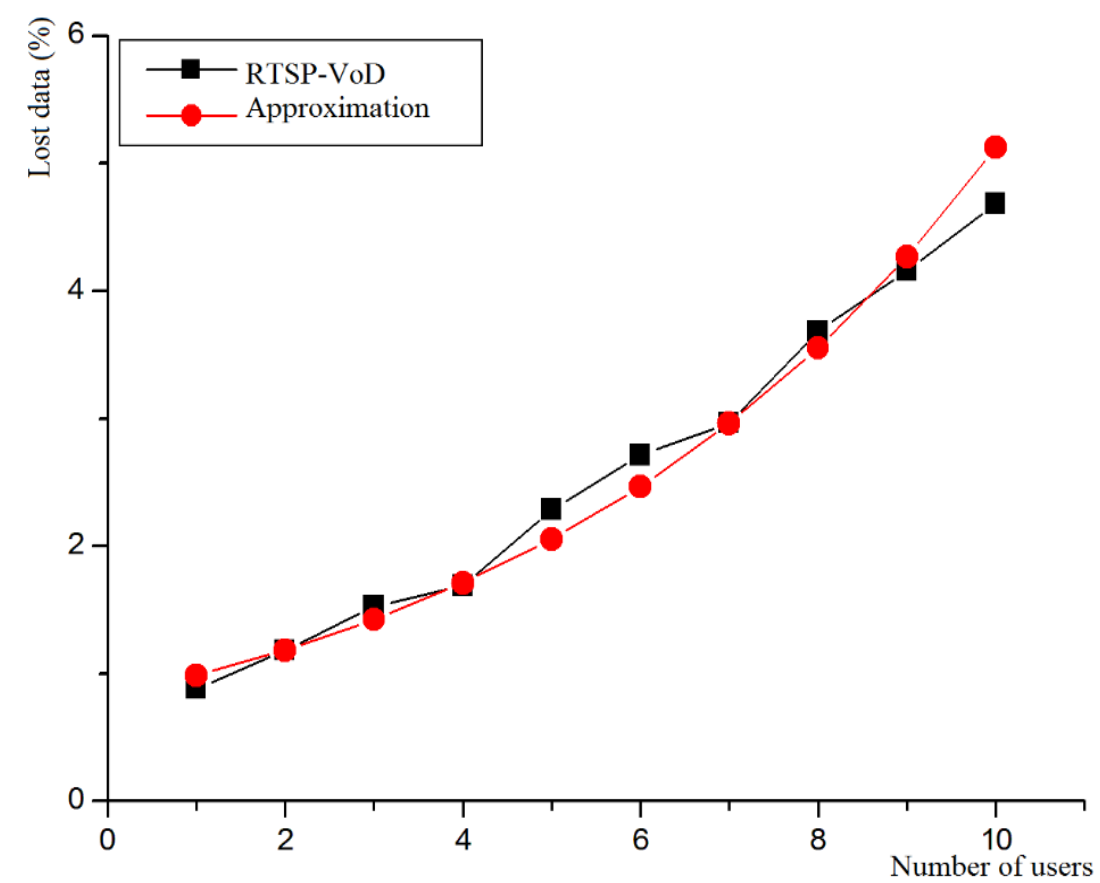

Figure. 10. Approximation for VoD sent through RTSP protocol through wired network. - Average relative error 5,56\%.

\section{CONCLUSIONS}

Through the use of the concept of linear regression and through the application of transformation of variables, four mathematical models were generated for the estimation of losses in the receivers, with a fairly accurate estimation level in each case since the error was reduced relative to values that oscillated between $5.56 \%$ and $6.23248 \%$.

This type of models can be used in the future within IPTV systems in order to estimate in advance the probable loss of data that may exist during the transmission of on demand television or video traffic, which may lead to routing protocols having the smart option of re-routing traffic through more appropriate channels.

Future research may involve the implementation of a losses system or model applied to IPTV by applying time series [6] and platforms based on Cognitive Radio Network (CRNs) [7]. 


\section{REFERENCES}

[1] J. Avellaneda, J. Rodríguez, D. López, Servicios de televisión sobre la plataforma de Internet (IPTV-IMS) usando el protocolo de flujo en tiempo real (RTSP) y el protocolo de transferencia de hipertexto (HTTP), Journal Información Tecnológica, Volume 25, Issue 1, pp. 67-76, 2014.

[2] S. Khan, R. Gaglianelo, M. Luna, Experiences with blending HTTP, RTS and IMS [IP multimedia system (IMS) infrastructure and services], IEEE Communications Magazine, Volume 45, Issue 3, pp. 122-128, 2007.

[3] G. Camarillo, T. Kauppinen, M. Kuparinen, I. Ivars, Towards an innovation oriented IP multimedia subsystem IMS [IP multimedia system (IMS) infrastructure and services], ], IEEE Communications Magazine, Volume 45, Issue 3, pp. 130-136, 2007.

[4] M. Siddiqui, S. Amin, C. Hong, A set-top box for end-to-end QoS management and home network gateway in IMS, IEEE Transactions on Consumer Electronics, Volume 55, Issue 2, pp. 527-534, 2009.

[5] VirtualBox, Oracle. [Online], recovered from: https://www.virtualbox.org/, 2013

[6] J. Salamanca, Y. Rodríguez, D. López, Development of an univariate method for predicting traffic behavior in wireless networks through statistical models, International Journal of Engineering and Technology (IJET), Volume 7, Issue 1, pp. 27-36, 2015.

[7] D. López, J. Ordoñez, E. Rivas, User characterization through dynamic Bayesian networks in cognitive radio wireless networks, International Journal of Engineering and Technology (IJET), Volume 8, Issue 4, pp. 1771-1783, 2016. 